\section{Research Square \\ Preprints are preliminary reports that have not undergone peer review. \\ They should not be considered conclusive, used to inform clinical practice, or referenced by the media as validated information.}

\title{
Predicting Progression to Severe COVID-19 Using the PAINT Score Based on Natural Killer Cells
}

\author{
Ming Wang \\ Sichuan University \\ Dongbo Wu \\ Sichuan University \\ Chang-Hai Liu \\ Sichuan University \\ Yan Li \\ The people's hospital of Qianxi \\ Jianghong $\mathrm{Hu}$ \\ The people's hospital of Duyun \\ Wei Wang \\ Sichuan University \\ Wei Jiang \\ Sichuan University \\ Qifan Zhang \\ Renmin Hospital of Wuhan University \\ Zhixin Huang \\ Renmin Hospital of Wuhan University \\ Lang Bai \\ Sichuan University \\ Hong Tang ( $\sim$ htang6198@hotmail.com ) \\ Sichuan University
}

\section{Research Article}

Keywords: COVID-19, SARS-CoV-2, NK cell, prediction.

Posted Date: July 1st, 2021

DOI: https://doi.org/10.21203/rs.3.rs-646188/v1

License: @ (i) This work is licensed under a Creative Commons Attribution 4.0 International License. Read Full License 


\section{Abstract}

Objectives: One of the major challenges in treating patients with coronavirus disease 2019 (COVID-19) is predicting the severity of disease. Natural killer (NK) cells are innate lymphocytes that respond to viral infection and might relate to COVID-19 disease severity. Therefore, we aimed to develop a new predictive score for progression from mild/moderate to severe COVID-19 based on NK cells information.

Method: In total, 239 hospitalized patients with COVID-19 from two medical center in China were retrospectively included. The prognostic effects of variables, including clinical data and laboratory findings from the electronic medical records of each hospital, were analyzed using Cox proportional hazards model and Kaplan-Meier methods. A prognostic score was developed to predict progression from mild/moderate to severe COVID-19.

Results: Among the 239 patients, 216 (90.38\%) patients had mild/moderate disease and 23 (9.62\%) progressed to severe disease. After adjusting multiple confounding factors, pulmonary disease, age $>75$, IgM, CD $16^{+} / \mathrm{CD}_{5} 6^{+} \mathrm{NK}$ cells and aspartate aminotransferase were independently predictors of progression to severe COVID-19. Based on these five factors, a new predictive score (the 'PAINT score') was established and showed a high predictive value ( $C$-index $=0.91,0.902 \pm 0.021, \mathrm{p}<0.001$ ). The PAINT score was validated using nomogram, bootstrap internal validations, calibration curves, decision curves and clinical impact curve, all of which confirmed its high predictive value.

Conclusions: The PAINT score for progression from mild/moderate to severe COVID-19 based on NK cell information may be helpful to identify patients at high risk of progression.

Trial registration: None

\section{Introduction}

Since December, 2019, a cluster of pneumonia cases of unknown origins in Wuhan was reported $(1,2)$. The pathogen of novel pneumonia was identified to be a novel $\beta$-coronavirus and is currently named severe acute respiratory syndrome coronavirus 2 (SARS-CoV-2), which shares a close phylogenetic similarity to SARS-CoV (3). The SARS-CoV-2 infection has been named coronavirus disease 2019 (COVID-19) by the World Health Organization (WHO) (4).

COVID-19 has now become a worldwide health concern. The estimated overall case-fatality rate for COVID-19 is about 1-2.3\%, which is similar to that of Spanish influenza (2-3\%) and much higher than that of seasonal influenza (0.1\%) (5-7). The severity of COVID-19 has been classified as mild, moderate, severe and critical per WHO-China Joint Mission (8). Among a total of 72314 case records from the Chinese Center for Disease Control and Prevention, about 81\% of COVID-19 cases were defined as mild; $14 \%$ of COVID-19 cases were severe, and $5 \%$ were critical (5). The overall hospital mortality of COVID-19 cases is about $15-20 \%$, but up to $40-49 \%$ among critical cases requiring Intensive Care Unit admission $(2,5)$. So it is important to evaluate the risk factors for disease progression in COVID-19 patients. Early identification of COVID-19 patients with possible progression of the disease is particularly important for optimal treatments choice and reducing the mortality.

Studies have revealed some changes in hematologic and immunologic tests and have investigated risk factors of mortality and outcome in patients with COVID-19 (2, 7, 9-11). Older age, high Sequential Organ Failure Assessment (SOFA) score, and d-dimer greater than $1 \mu \mathrm{g} / \mathrm{mL}$, lymphocytopenia and history of coronary vascular disease were reported to increase the risk of death in patients with COVID-19 (7, 9-11).

Moreover, predicting score models have been used to predict prognosis in COVID-19 patients and other diseases (12-15). However, the risk factors related to the progression of COVID-19 symptoms from mild/moderate to severe disease states are still limited and needed to access. The immune response and the inflammatory cytokines were important to elucidate mechanisms of host responses and pathogenesis of COVID-19 (10, 16-18). Exception for decreased T cells, Natural killer (NK) cell immunotypes was reported related to COVID-19 disease severity recently $(16,19)$. We enrolled patients with COVID-19 from two medical center in China and aimed to evaluate the risk factors for disease progression to severe-stage based on the new combined score based on NK cells.

\section{Materials And Methods}

\section{Study design and participants}

This study was a retrospective, multi-center study. The laboratory-confirmed COVID-19 admitted cases from Renmin Hospital of Wuhan University and West China Hospital of Sichuan University. We included adult patients (aged $\geq 18$ years) admitted between February 6 and April 6, 2020, with laboratory-confirmed SARS-CoV-2 infection by RT-PCR. 
The diagnosis of COVID-19 was made according to WHO interim guidance (20). The severity of COVID-19 was assessed according to the Seventh Version of the Novel Coronavirus Pneumonia Diagnosis and Treatment Guidance from the National Health Commission of China (21). According to the guideline, patients were categorized into mild, moderate, severe, or critical group upon admission (21).

\section{Data collection}

The clinical data, laboratory data and radiological data of all COVID-19 patients were obtained from the electronic medical records of each designated hospital. Data were reviewed and verified by a team of physicians (Dongbo Wu, Wei Jiang, Changhai Liu, Ming Wang and Lang Bai). Any missing or uncertain records were collated and clarified through communication with local medical staff or patients and their families.

Detailed demographics information, comorbidities, symptoms, and disease severity of all patients were recorded or diagnosed on admission. The clinical and virological characteristics were recorded, e.g., age, sex, past medical history, and clinical findings, e.g., White blood cell (WBC), neutrophil count (NEU), lymphocyte count (LYM), hemoglobin (HGB), platelet count (PLT), prothrombin time (PT), D-dimer, alanine aminotransferase (ALT), aspartate aminotransferase (AST), $y$-glutamyl transpeptidase (GGT), albumin (ALB), total bilirubin (TBIL), Direct bilirubin (DBIL), uric acid (UA), creatinine (Cr), creatine kinase (CK), lactate dehydrogenase (LDH), Brain Natriuretic Peptide (BNP), procalcitonin (PCT), c-reactive protein (CRP), Neutrophils/ Lymphocyte ratio (NLR), other biochemical parameters and SARS-CoV2 RNA test. There were no cases lost to follow-up in this study.

\section{Statistical analysis}

Baseline clinical characteristics and the outcomes of patients were reported. Categorical data are presented as frequencies (percentages); continuous variables as median (range, minimum-maximum). The demographic, clinical and laboratory characteristics of COVID-19 patients were compared in each group. The Mann Whitney U test was used to compare continuous variables. The $\chi^{2}$ test with Yates' correction was used for $2 \times 2$ contingency data, and Pearson's $\chi^{2}$ test was used for contingency data for variables with more than two categories.

To explore risk factors, or their interactions, associated with severity of COVID-19 patients, univariable and multivariable logistic regression models were used to estimate odds ratios (ORs) and 95\% Cls. The Cox proportional hazards model was constructed sequentially with variables introduced individually, and a significance level of $p>0.05$ was used to remove the variables from the model. A final model selection was performed by a backward selection of all factors. Schoenfeld and Martingale residuals were used to check the proportional hazards assumption and nonlinearity, respectively.

Survival curves were compared using the Kaplan-Meier method (log-rank test) since time-to-mortality, and time-to-event is crucial in interpreting the results. Estimates of adjusted hazard ratios (HRs), $95 \% \mathrm{Cl}$, and P value are displayed. The Harrell's concordance index (Cindex) was used to assess the score's discrimination ability. C-index values and the corresponding $95 \%$ Cls were estimated for each main study time point. Moreover, bootstrap, calibration curve, decision curve and the clinical impact curve were applied to verify the nomogram. A two-sided $p<0.05$ was considered statistically significant. All statistical analyses were done using R software (version 3.5.2, http://CRAN.Rproject.org, R Foundation, Vienna, Austria).

\section{Results}

\section{Demographic and clinical characteristics of the study population}

In total, 239 COVID-19 patients were included in this study. In the present cohort, 216 (90.38\%) patients were mild/moderate cases, and 23 (9.62\%) cases with progression to severe. Demographic and clinical characteristics of the study population are presented in table 1 . The median age was 58 years (range, 26-90 years), and 58.20\% (139/239) were male. The median max temperature was $38^{\circ} \mathrm{C}($ range, 36.0-41.0).

When comparing demographic data at admission, progression to severe cases were more likely to be male patients and older age ( $>75$ years) than patients without progression $(P<0.05$, table 1$)$. The clinical manifestations were mainly presented as the followings (Table 1$)$ : fever $77.8 \%$ (186/239), cough $60.3 \%$ (144/239), expectoration $23.8 \%$ (57/239), dyspnea 10.5\% (25/239), chest pain $4.6 \%(11 / 239)$, angina $4.2 \%$ (11/239), fatigue $28.5 \%(68 / 239)$, myalgia $9.2 \%$ (22/239), headache 5.0\% (12/239), vomit 1.7\% (4/239) and diarrhea $18 \%(43 / 239)$.

The clinical characteristics of the study population were summarized in table 2 . When comparing biochemical indexes of COVID-19 between moderate cases with and without progression, we found that there were significant differences in lymphocytes, NLR, CRP, AST, TBIL, DBIL, Cr, urea, glucose, sodium, $\mathrm{PT}, \mathrm{CD} 3^{+} \mathrm{T}$ cell, $\mathrm{CD} 4^{+} \mathrm{T}$ cell, $\mathrm{CD} 8^{+} \mathrm{T}$ cell, $\mathrm{CD} 19^{+} \mathrm{T}$ cell, $\mathrm{CD} 16^{+} / \mathrm{CD}^{2} 6^{+} \mathrm{NK}$ cell between patients with or without progression (all $P<0.05$ ), detailed information were listed in Table 2 . 
When exploring risk factors of progression from mild/moderate cases into severe COVID-19 cases, we compared the demographic and clinical data between moderate cases and progression to sever cases. Using univariant and multivariant COX regression model, the results showed a significant difference in pulmonary disease $(11.20,95 \% \mathrm{Cl} 2.50-49.70, \mathrm{p}=0.001)$, age over 75 (3.92, 95\% $\mathrm{Cl} 1.61-9.73$, $\mathrm{p}=0.003), \operatorname{lgM}(6.31,95 \% \mathrm{Cl} 1.99-19.60, \mathrm{p}=0.002), \mathrm{CD}_{16}{ }^{\prime} / \mathrm{CD} 56^{+} \mathrm{NK}$ cell $(3.40,95 \% \mathrm{Cl} 1.31-9.13, \mathrm{p}=0.014)$ and AST $(4.60,95 \% \mathrm{Cl} 1.31-16.00$, $\mathrm{p}=0.018$ ) (Table 3), which were the 5 independent risk factors for progression from mild/moderate cases into severe cases (Fig. 1). However, there were no significant impacts of other variables showed in our study population (see Supplementary material, Table S1). We also used global Schoenfeld test cox diagnostics deviance and ox proportional hazards model fit to evaluate these five independent risk factors for progression from mild/moderate cases into severe cases, suggesting good performances (see Supplementary material, Fig. S1-S3).

Moreover, the Kaplan-Meier survival curve analysis and log-rank test showed a significant difference in survival curve in COVID-19 patients categorized by the Pulmonary disease, Age, IgM, CD16+/CD56+ NK cells and AST, respectively (see Supplementary material, Fig. S4 a-e).

\section{Development of predictive score for progression from moderate cases into severe cases}

Predictors including pulmonary disease, Age, IgM, CD16+/CD56+ NK cells and AST were enrolled in the development of predictive score for COVID-19 patients' progression from mild/moderate cases into severe cases. The new predictive score (Pulmonary disease, Age, IgM, $\mathrm{CD} 16^{+} / \mathrm{CD}^{+} 6^{+} \mathrm{NK}$ cell, AST; PAINT score $)=($ pulmonary disease $) * 2.4174+($ Age $>75) * 1.3594+(\operatorname{lgM}<0.84) * 1.8399+\left(\mathrm{CD} 16^{+} / \mathrm{CD}^{2} 6^{+} \mathrm{NK}\right.$ cell<116.5)*1.2246+(AST>25)*1.5182.

The points contributed for each variable are shown in figure S5. To demonstrate the ability of the newly predictive score to find more severe patients for early clinical treatment, Kaplan-Meier survival curve analysis was used to find the best cut-off value; a value of 14.687 points was found to divide the patients into mild/moderate and progression to sever groups $(P=0.001, \mathrm{Fig}$. 2).

We performed ROC analysis to evaluate the efficacy of PAINT score model for predicting COVID-19 patients' progression from mild/moderate cases into severe cases. We compared the PAINT score with qSOFA and CURB-65 ((confusion, uraemia, respiratory rate, BP, age>65 years)) score. As demonstrated in fig. 3, the $\mathrm{C}$-index of the newly predictive progression model for predicting progression from mild/moderate cases into severe cases was $0.902 \pm 0.021$. However, the C-index of qSOFA and CURB- 65 score for the prediction of progression was $0.534 \pm 0.027$ and $0.561 \pm 0.058$. We also compare the newly predictive progression model with the 5 the independent risk factors (pulmonary disease, Age, $\operatorname{lgM}, \mathrm{CD} 16+/ \mathrm{CD} 56+\mathrm{NK}$ cells and AST), the C-index for the prediction of progression was $0.5432 \pm 0.034,0.639 \pm 0.052,0.683 \pm 0.044,0.647$ \pm 0.050 and $0.716 \pm 0.036$,respectively (see Supplementary material, Table S2). These findings suggested that the PAINT score might be suitable for predicting progression from mild/moderate cases into severe cases.

For internal validation of the ability of the newly predictive progression model, we performed concordance index analysis to evaluate the discrimination for the PAINT score. The better discrimination was observed in our PAINT score than qSOFA and CURB-65 score (Fig. 4a). Moreover, we performed 1000 times bootstrap internal validations, our newly predictive PAINT score also showed better discrimination (Fig. 4b)

\section{Nomogram, calibration, decision curve and clinical impact curve for progression from mild/moderate cases into severe cases}

In our study population, we used 5 variables (Pulmonary disease, Age, IgM, CD16+/CD56+ NK cells and AST) to predict 28 days progression from mild/moderate cases into severe cases. According to the construction principle of nomogram score, each variable will be given different points and weights. The nomogram score was shown in Fig. $5 \mathrm{a}$. We can evaluate the score of each variable in turn according to their clinical characteristics and examination results, and then summarize according to the total score of 5 variables. Based on the total score, the patient can determine the probability of progression to severe COVID-19 cases. The calibration curves for 28 days progression was also performed well in the internal validation set (Fig. 5b). Nomograms and decision curves analyses were also performed well in the PAINT score (Fig. 5c). Clinical impact curves were proposed to assess the clinical usefulness of the risk prediction nomogram (Fig. 5d).

\section{Discussion}

Though using univariant and multivariant COX regression model, we identified five independent risk factors (pulmonary disease, age, IgM, $\mathrm{CD} 16^{+} / \mathrm{CD} 6^{+} \mathrm{NK}$ cell and AST) for progression into COVID-19 severe cases in the present study. We developed a newly of predictive PAINT score for progression into severe cases and found a value of 14.687 points to divide the patients into mild/moderate and progression to sever groups. Moreover, we also established a newly nomogram score to predict 28 days progression from mild/moderate cases into severe cases. These results may be important to predict progression for moderate COVID-19 patients into sever, and may be helpful to identify progression cases timely to improve the prognosis in the clinical practice.

Page 4/14 
Coronavirus SARS-CoV-2, the third coronavirus that has caused severe disease in human globally, is the etiologic agent for COVID-19, which has caused over 1 million persons died in the past 12 months $(22,23)$. SARS-CoV-2 is a single-stranded RNA virus, which infected cells though its structural spike (S) protein binding the angiotensin-converting enzyme 2 (ACE2) receptor (24). Then type 2 transmembrane serine protease (TMPRSS2) receptor cleaved ACE2, activating S protein which promote virus uptake and mediate SARS-CoV-2 entry into host cells $(2,24)$. Both ACE2 and TMPRSS2 were expressed in host cells, particularly alveolar epithelial type II cells of COVID-19 patients (17). COVID-19 has various clinical manifestation, the common symptom in hospitalized patients include fever (70\%-90\%), dry cough (60\%-86\%), shortness of breath (53\%-80\%), fatigue (38\%), myalgias (15\%-44\%), nausea/vomiting or diarrhea (15\%-39\%), headache, weakness (25\%), and rhinorrhea (7\%) (2). In a retrospective study of 548 patients with COVID-19 in China, most of the severe/critical and fatal patients presented with sputum and dyspnea much more often than mild/moderate and survival subjects on admission (4). Eighty-one percentages of patients had mild manifestations, $14 \%$ had severe manifestations, and $5 \%$ had critical manifestations (defined by respiratory failure, septic shock, and/or multiple organ dysfunction). A study of 20133 hospitalized in UK reported that the most common major comorbidities were chronic cardiac disease (30.9\%), diabetes (20.7\%), chronic pulmonary disease excluding asthma (17.7\%), chronic kidney disease (16.2\%) (25). In our study population, the most common major comorbidities were pulmonary disease. Moreover, we find pulmonary disease was the independent risk factors for progression into server COVID-19 cases. The limited sample size may be responsible for this difference with the previous UK report (25).

We used Cox regression methods to explore the risk factors related with progression to severe COVID-19 case. The risk factors related with progression were reported in non-severe COVID-19 patient, such as lymphocyte count, neutrophil count, CD $4^{+}$and CD $8^{+}$T cell counts, CRP, Ddimer, interleukin-6, interleukin-8, lactate dehydrogenase, age, dyspnea on admission, hypertension (10, 26-28). From the present study, there were significant differences of lymphocytes, NLR, CRP, AST, Cr, CD $3^{+} \mathrm{T}$ cell, CD $4^{+} \mathrm{T}$ cell, CD8 ${ }^{+} \mathrm{T}$ cell, CD19 $9^{+} \mathrm{T}$ cell, CD $16^{+} / \mathrm{CD} 56^{+} \mathrm{NK}$ cell in mild/moderate COVID-19 cases with and without progression. We also find that comorbidity of pulmonary had an impact on the risk of progression. In order to predict the progression risk, we develop the newly predictive PAINT score. Using a value of 14.687 points, we could divide the patients into mild/moderate and progression to severe groups, with a higher C-index $(0.902 \pm 0.021)$ when compared with qSOFA $(0.534 \pm 0.027)$ and CURB-65 score $(0.561 \pm 0.058)$. The internal validation of discrimination and 1000 times bootstrap showed good ability of our newly predictive progression model. In another study, four variables (comorbidity, dyspnea on admission, lactate dehydrogenase and lymphocyte count) included in the predictive model. Total score of 6 points were used to divided patients into high-risk and low-risk groups (26). Moreover, the risk factors for progression in to severe illness in COVID-19 patients with cancer not only included the previous variables of older age; interleukin 6, procalcitonin, and D-dimer; and lymphocytes, but also included tumour stage, tumour necrosis factor a, $\mathrm{N}$-terminal pro-B-type natriuretic peptide, $\mathrm{CD} 4^{+} \mathrm{T}$ cells and albumin-globulin ratio (29).

The immune response to SARS-CoV-2 is key for control and resolution of COVID-19 infection. The inflammatory cytokines (IL-6, TNF-a, IL-10, IL-2, IL-7, CXCL10, CCL2, CCL3, IP-10, MCP-3) are higher severe COVID-19cases ("cytokine storm") and may be associated with pulmonary inflammation and progression in COVID-19 patients $(1,10,15,30)$. The T cell also played important roles in immune response to SARS-CoV-2 infection. The lymphocytopenia was found to be one of the most common features in laboratory tests of COVID-19 patients, and the reduced $\mathrm{CD}^{+}$and $\mathrm{CD}^{+} \mathrm{T}$ cell counts was predictive factor of disease progression $(10,11)$. Exception for decreased levels of $\mathrm{CD} 3^{+} / \mathrm{CD}^{+} \mathrm{T}^{-}$ lymphocytes, $\mathrm{CD}^{+} / \mathrm{CD} 8^{+} \mathrm{T}$ lymphocytes and CD $19^{+} \mathrm{B}$ lymphocytes, CD $16^{+} / \mathrm{CD}^{2} 6^{+} \mathrm{NK}$ cells were also decreased in the peripheral blood of COVID-19 patients which may play critical roles in the inflammatory cytokine storm (18). NK immunotypes was related to COVID-19 disease severity and high expression of perforin, NKG2C, and Ksp37 in NK cells may reflect increased presence of adaptive NK cells in circulation of patients with severe disease (16). This may provide the mechanisms of NK cell activation in COVID-19 and their potential roles in host

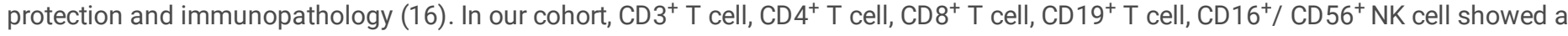
significant difference in mild/moderate COVID-19 cases with and without progression. Moreover, $\mathrm{CD}_{16}{ }^{+} / \mathrm{CD}^{2} 6^{+} \mathrm{NK}$ cell was also an independent risk factors for progression from moderate cases into severe cases. The detailed map of the NK cell activation landscape in COVID-19 disease might be used as meaningful indicators for progression.

Our study has several limitations. First, the study population only included patients within Renmin Hospital of Wuhan University (Central China region) and West China Hospital of Sichuan University (Southwest China region). The study sample size was relatively small. Second, the data were obtained from the electronic medical data base of each designated hospital. Some cases had incomplete records of the exposure history and laboratory examination and some patients were diagnosed in outpatient department where incomplete medical records and laboratory testing was briefly documented. Third, because many patients remained in the hospital and the outcomes were unknown at the time of data collected. Forth, the detail information of follow-up is not included in our study results. So, the uncertainty of bias might have inevitably affected our assessment. Further evaluation may be needed to validate our predictive model.

\section{Conclusion}


In conclusion, pulmonary disease, Age, IgM, CD16+/CD56+ NK cells and AST were independent predictors of progression for patients with COVID-19 in the present study. Predictive model for progression to severe COVID-19 based on the PAINT score might be helpful to identify progression cases. Moreover, more intensive surveillance and appropriate therapy should be considered in patients at high risk of progression to improve the prognosis in the clinical practice. Future studies with larger numbers of patients will be useful for updating and validating this PAINT score to improve predictions of patients with progression to severe COVID-19.

\section{Abbreviations}

SARS-CoV-2: severe acute respiratory syndrome coronavirus 2.

COVID-19: coronavirus disease 2019.

WHO: World Health Organization.

SOFA: Sequential Organ Failure Assessment

NK: Natural killer.

ORs: odds ratios.

HRs: hazard ratios.

ACE2: angiotensin-converting enzyme 2.

TMPRSS2: type 2 transmembrane serine protease.

\section{Declarations}

\section{Ethics approval and consent to participate}

This study was approved by the Ethics Committee of West China Hospital of Sichuan University (NO. 2020-444), and was allowed exception to the requirement of informed consents for this study. All research was conducted in accordance with the Declaration of Helsinki.

Ethics approval and consent to participate: Yes, supplementary data.

Consent for publication: None, present study was retrospective study design and did not contains specific personal medical information (video or image) about an identifiable living individual.

Availability of data and materials: Yes, supplementary data. All data generated or analyzed during this study are included in this published article and its supplementary information files.

Competing interests: No.

Funding: This work was supported by the Special funds for Prevention and Control of COVID-19 of Sichuan University and West China Hospital (NO. 2020scunCoV10004 and NO. HX-2019-nCoV-010) and the China Postdoctoral Science Foundation (2020M670059ZX).

Author contributions: Hong Tang, Bai Lang, Ming Wang, Dongbo Wu and Changhai Liu designed the study, analyzed the data, wrote the paper冈review \& editing the paper. Ming Wang, Yan Li, Jianghong Hu, Wei Jang and Wang Wei performed data analysis, the literature search and constructed the figures. Zhixin Huang, Qifan Zhang, Dongbo Wu, Wang Wei, Yan Li, Jianghong Hu, and Ming Wang collected the data in Wuhan, analyzed the data and designed the study. Dongbo Wu, Ming Wang, Wei Jiang and Changhai Liu collected the data in Chengdu.

Acknowledgements: We would like to thank all study participants, their families, medical staff, and participating hospitals for their support in the present study.

\section{References}

1. Huang C, Wang Y, Li X, Ren L, Zhao J, Hu Y, et al. Clinical features of patients infected with 2019 novel coronavirus in Wuhan, China. Lancet. 2020;395(10223):497-506. 
2. Wiersinga WJ, Rhodes A, Cheng AC, Peacock SJ, Prescott HC. Pathophysiology, Transmission, Diagnosis, and Treatment of Coronavirus Disease 2019 (COVID-19): A Review. Jama. 2020;324(8):782-93.

3. Liu Y, Yan LM, Wan L, Xiang TX, Le A, Liu JM, et al. Viral dynamics in mild and severe cases of COVID-19. The Lancet Infectious diseases. 2020;20(6):656-7.

4. Chen R, Sang L, Jiang M, Yang Z, Jia N, Fu W, et al. Longitudinal hematologic and immunologic variations associated with the progression of COVID-19 patients in China. J Allergy Clin Immunol. 2020;146(1):89-100.

5. Wu Z, McGoogan JM. Characteristics of and Important Lessons From the Coronavirus Disease 2019 (COVID-19) Outbreak in China: Summary of a Report of 72314 Cases From the Chinese Center for Disease Control and Prevention. Jama. 2020.

6. Gates B. Responding to Covid-19 - A Once-in-a-Century Pandemic? The New England journal of medicine. 2020;382(18):1677-9.

7. Chang MC, Park YK, Kim BO, Park D. Risk factors for disease progression in COVID-19 patients. BMC infectious diseases. 2020;20(1):445.

8. WorldHealthOrgnization. Report of the WHO-China Joint Mission on Coronavirus Disease 2019 (COVID-19)2020; (28 February 2020): [WHO Coronavirus Disease (COVID-19) Dashboard pp.]. Available from: https://www.who.int/publications/i/item/report-of-the-whochina-joint-mission-on-coronavirus-disease-2019-(covid-19).

9. Zhou F, Yu T, Du R, Fan G, Liu Y, Liu Z, et al. Clinical course and risk factors for mortality of adult inpatients with COVID-19 in Wuhan, China: a retrospective cohort study. Lancet. 2020;395(10229):1054-62.

10. Zhang X, Tan Y, Ling Y, Lu G, Liu F, Yi Z, et al. Viral and host factors related to the clinical outcome of COVID-19. Nature. 2020;583(7816):437-40.

11. Guan WJ, Ni ZY, Hu Y, Liang WH, Ou CQ, He JX, et al. Clinical Characteristics of Coronavirus Disease 2019 in China. The New England journal of medicine. 2020;382(18):1708-20.

12. Liu C, Li L, Song K, Zhan ZY, Yao Y, Gong H, et al. A nomogram for predicting mortality in patients with COVID-19 and solid tumors: a multicenter retrospective cohort study. J Immunother Cancer. 2020;8(2).

13. Chen R, Liang W, Jiang M, Guan W, Zhan C, Wang T, et al. Risk Factors of Fatal Outcome in Hospitalized Subjects With Coronavirus Disease 2019 From a Nationwide Analysis in China. Chest. 2020;158(1):97-105.

14. Jehi L, Ji X, Milinovich A, Erzurum S, Rubin BP, Gordon S, et al. Individualizing Risk Prediction for Positive Coronavirus Disease 2019 Testing: Results From 11,672 Patients. Chest. 2020;158(4):1364-75.

15. Vultaggio A, Vivarelli E, Virgili G, Lucenteforte E, Bartoloni A, Nozzoli C, et al. Prompt Predicting of Early Clinical Deterioration of Moderate-to-Severe COVID-19 Patients: Usefulness of a Combined Score Using IL-6 in a Preliminary Study. J Allergy Clin Immunol Pract. 2020;8(8):2575-81.e2.

16. Maucourant C, Filipovic I, Ponzetta A, Aleman S, Cornillet M, Hertwig L, et al. Natural killer cell immunotypes related to COVID-19 disease severity. Science immunology. 2020;5(50).

17. Sungnak W, Huang N, Bécavin C, Berg M, Queen R, Litvinukova M, et al. SARS-CoV-2 entry factors are highly expressed in nasal epithelial cells together with innate immune genes. Nature medicine. 2020;26(5):681-7.

18. Wu Y, Huang X, Sun J, Xie T, Lei Y, Muhammad J, et al. Clinical Characteristics and Immune Injury Mechanisms in 71 Patients with COVID-19. mSphere. 2020;5(4).

19. Li M, Guo W, Dong Y, Wang X, Dai D, Liu X, et al. Elevated Exhaustion Levels of NK and CD8(+) T Cells as Indicators for Progression and Prognosis of COVID-19 Disease. Frontiers in immunology. 2020;11:580237.

20. WorldHealthOrgnization. Clinical management of severe acute respiratory infections when novel coronavirus is suspected: What to do and what not to do2020; (11 February 2020). Available from:

https://www.who.int/csr/disease/coronavirus_infections/InterimGuidance_ClinicalManagement_NovelCoronavirus_11Feb13u.pdf? ua $=1 \&$ ua $=1$.

21. NationalHealthCommissionofthePeople'sRepublicofChina. Chinese management guideline for COVID-19 (Trail version 7.0 ) 2020 [Available from:

http://www.nhc.gov.cn/yzygj/s7653p/202003/46c9294a7dfe4cef80dc7f5912eb1989/files/ce3e6945832a438eaae415350a8ce964.pdf.

22. Laing AG, Lorenc A, Del Molino Del Barrio I, Das A, Fish M, Monin L, et al. A dynamic COVID-19 immune signature includes associations with poor prognosis. Nature medicine. 2020;26(10):1623-35.

23. WHO Coronavirus Disease (COVID-19) Dashboard [Internet]. 2020 [cited October 8 2020]. Available from: https://covid19.who.int/.

24. Hoffmann M, Kleine-Weber H, Schroeder S, Krüger N, Herrler T, Erichsen S, et al. SARS-CoV-2 Cell Entry Depends on ACE2 and TMPRSS2 and Is Blocked by a Clinically Proven Protease Inhibitor. Cell. 2020;181(2):271 - 80.e8. 
25. Docherty AB, Harrison EM, Green CA, Hardwick HE, Pius R, Norman L, et al. Features of 20133 UK patients in hospital with covid-19 using the ISARIC WHO Clinical Characterisation Protocol: prospective observational cohort study. Bmj. 2020;369:m1985.

26. Ji M, Yuan L, Shen W, Lv J, Li Y, Chen J, et al. A predictive model for disease progression in non-severely ill patients with coronavirus disease 2019. Eur Respir J. 2020;56(1).

27. Yu C, Zhou M, Liu Y, Guo T, Ou C, Yang L, et al. Characteristics of asymptomatic COVID-19 infection and progression: A multicenter, retrospective study. Virulence. 2020;11(1):1006-14.

28. Moutchia J, Pokharel P, Kerri A, McGaw K, Uchai S, Nji M, et al. Clinical laboratory parameters associated with severe or critical novel coronavirus disease 2019 (COVID-19): A systematic review and meta-analysis. PloS one. 2020;15(10):e0239802.

29. Tian J, Yuan X, Xiao J, Zhong Q, Yang C, Liu B, et al. Clinical characteristics and risk factors associated with COVID-19 disease severity in patients with cancer in Wuhan, China: a multicentre, retrospective, cohort study. The Lancet Oncology. 2020;21(7):893-903.

30. Yang Y, Shen C, Li J, Yuan J, Wei J, Huang F, et al. Plasma IP-10 and MCP-3 levels are highly associated with disease severity and predict the progression of COVID-19. J Allergy Clin Immunol. 2020;146(1):119 - 27.e4.

\section{Tables}

Table 1 Demographic and clinical characteristics of the study population.

\begin{tabular}{|c|c|c|c|c|}
\hline Characteristic & $\begin{array}{l}\text { All patients } \\
(\mathrm{n}=239)\end{array}$ & $\begin{array}{l}\text { Without progression } \\
(\mathrm{n}=216)\end{array}$ & $\begin{array}{l}\text { Progression to severe } \\
(n=23)\end{array}$ & $P$ value \\
\hline Sex & $139(58.2)$ & $130(60.2)$ & $9(39.1)$ & 0.038 \\
\hline \multicolumn{5}{|l|}{ Male n (\%) } \\
\hline Age (year) & $58(26-90)$ & $57.5(26-88)$ & $62(29-90)$ & 0.010 \\
\hline Max temperature $\left({ }^{\circ} \mathrm{C}\right)$ & $38.0(36.0-41.0)$ & $38.0(36.0-39.8)$ & $38.3(36.5-41.0)$ & 0.129 \\
\hline \multicolumn{5}{|c|}{ Clinical manifestations, n (\%) } \\
\hline Fever & $186(77.8)$ & $168(77.8)$ & $18(78.3)$ & 0.688 \\
\hline Cough & $144(60.3)$ & $127(58.8)$ & $17(73.9)$ & 0.175 \\
\hline Expectoration & $57(23.8)$ & $50(23.1)$ & $7(30.4)$ & 0.642 \\
\hline Dyspnea & $25(10.5)$ & $23(10.7)$ & $2(8.7)$ & 0.001 \\
\hline Chest pain & $11(4.6)$ & $10(4.6)$ & $1(4.3)$ & 0.982 \\
\hline Angina & $10(4.2)$ & $8(3.7)$ & $2(8.7)$ & 0.662 \\
\hline Fatigue & $68(28.5)$ & $58(26.9)$ & $10(43.5)$ & 0.206 \\
\hline Myalgia & $22(9.2)$ & $22(10.2)$ & 0 & 0.221 \\
\hline Headache & $12(5.0)$ & $12(5.6)$ & 0 & 0.476 \\
\hline Vomit & $4(1.7)$ & $3(1.4)$ & $1(4.3)$ & 0.421 \\
\hline Diarrhea & $43(18.0)$ & $40(18.5)$ & $3(13.0)$ & 0.787 \\
\hline \multicolumn{5}{|l|}{ Comorbidities, n (\%) } \\
\hline Hypertension & $66(27.6)$ & $60(27.8)$ & $6(26.1)$ & 0.782 \\
\hline Diabetes mellitus & $25(10.5)$ & $20(9.3)$ & $5(21.7)$ & 0.285 \\
\hline Cardiac disease & $20(8.4)$ & $19(8.8)$ & $1(4.3)$ & 0.509 \\
\hline Pulmonary disease & $10(4.2)$ & $7(3.2)$ & $3(13.0)$ & 0.035 \\
\hline Liver disease & $11(4.6)$ & $8(3.7)$ & $3(13.0)$ & 0.027 \\
\hline
\end{tabular}

Table 2 The lab test and clinical characteristics of the study population. 


\begin{tabular}{|c|c|c|c|c|}
\hline Laboratory findings & $\begin{array}{l}\text { All patients } \\
(n=239)\end{array}$ & $\begin{array}{l}\text { Without progression } \\
(n=216)\end{array}$ & $\begin{array}{l}\text { Progression to severe } \\
(n=23)\end{array}$ & P value \\
\hline Systolic pressure $(\mathrm{mmHg})$ & $129.00(87-195)$ & $128(87-195)$ & $133(108-151)$ & 0.775 \\
\hline Diastolic pressure $(\mathrm{mmHg})$ & $78(51-114)$ & $78(51-106)$ & $75(60-114)$ & 0.131 \\
\hline Rhythm of the heart (beats/min) & $85(37-140)$ & $85(37-140)$ & $86(75-114)$ & 0.796 \\
\hline Breathing rate (beats/min) & $20(15-32)$ & $20(15-25)$ & $20(16-32)$ & 0.008 \\
\hline CURB-65 score & $0(0-3)$ & $0(0-2)$ & $0(0-3)$ & 0.497 \\
\hline qSOFA score & $0(0-3)$ & $0(0-2)$ & $0(0-3)$ & 0.035 \\
\hline WBC $\left(\times 10^{9} / L\right)$ & $5.07(1.23-17.48)$ & $5.06(1.23-17.48)$ & $5.27(2.55-11.38)$ & 0.529 \\
\hline Neutrophils $\left(\times 10^{9} / \mathrm{L}\right)$ & $3.08(0.69-16.18)$ & $3.03(0.69-16.18)$ & $3.75(1.16-9.53)$ & 0.672 \\
\hline Percentage of neutrophils (\%) & $63.5(23.1-97.7)$ & $62.0(23.1-97.7)$ & $68.9(35.9-94.3)$ & 0.000 \\
\hline Lymphocyte $\left(\times 10^{9} / \mathrm{L}\right)$ & $1.22(0.29-3.48)$ & $1.29(0.31-3.48)$ & $0.94(0.29-1.64)$ & 0.001 \\
\hline NLR & $2.41(0.42-32.21)$ & $2.28(0.42-27.90)$ & $3.47(0.72-32.21)$ & 0.019 \\
\hline Percentage of lymphocyte (\%) & $25.9(2.9-59.2)$ & $26.6(3.3-59.2)$ & $20.7(2.9-50.2)$ & 0.000 \\
\hline $\mathrm{HGB}(\mathrm{g} / \mathrm{L})$ & $125(65-159)$ & $125(65-159)$ & $119(90-149)$ & 0.545 \\
\hline $\operatorname{PLT}\left(\times 10^{9} / \mathrm{L}\right)$ & $217(27-608)$ & $219.5(27-608)$ & $210(128-490)$ & 0.078 \\
\hline $\mathrm{CRP}(\mathrm{mg} / \mathrm{L})$ & $38.1(3-181)$ & $35.9(3-181)$ & $64.7(6-171)$ & 0.058 \\
\hline ALT (IU/L) & $22(6-274)$ & $21(6-274)$ & $28(9-162)$ & 0.171 \\
\hline AST (IU/L) & $22(10-312)$ & $21(10-312)$ & $30(13-104)$ & 0.017 \\
\hline GGT (IU/L) & $24(0.85-3-8)$ & $23(0.85-309)$ & $28(10-105)$ & 0.084 \\
\hline TBIL $(\mu \mathrm{mol} / \mathrm{L})$ & $10.0(2.5-36.8)$ & $10.1(2.5-36.8)$ & $9.7(6.0-19.1)$ & 0.010 \\
\hline DBIL $(\mu \mathrm{mol} / \mathrm{L})$ & $3.5(0.6-13.6)$ & $3.5(0.6-13.6)$ & $4.1(2.6-9.2)$ & 0.020 \\
\hline Urea $(\mathrm{mmol} / \mathrm{L})$ & $4.3(1.7-39.2)$ & $4.16(1.70-39.2)$ & $5(2.91-28.1)$ & 0.010 \\
\hline $\mathrm{Cr}(\mu \mathrm{mol} / \mathrm{L})$ & $58(35-1045)$ & $58(35-1045)$ & $65(37-231)$ & 0.017 \\
\hline $\mathrm{UA}(\mu \mathrm{mol} / \mathrm{L})$ & $267(69-683)$ & $267(69-683)$ & $274(106-536)$ & 0.293 \\
\hline Glucose $(\mathrm{mmol} / \mathrm{L})$ & $5.37(3.06-34.2)$ & $5.36(3.06-34.20)$ & $5.55(3.12-23.04)$ & 0.001 \\
\hline Potassium ( $\mu \mathrm{mol} / \mathrm{L})$ & $3.97(2.52-7.97)$ & $3.96(2.52-7.97)$ & $4.07(3.44-5.84)$ & 0.402 \\
\hline Sodium $(\mathrm{mmol} / \mathrm{L})$ & $142(126-154)$ & $142(126-154)$ & $139(131-148)$ & 0.004 \\
\hline Calcium (mmol/L) & $2.16(1.53-4.35)$ & $2.17(1.53-4.35)$ & $2.03(1.89-4.35)$ & 0.525 \\
\hline Magnesium (mmol/L) & $0.84(0.21-2.07)$ & $0.84(0.21-1.13)$ & $0.87(0.63-2.07)$ & 0.926 \\
\hline Cholesterol (mmol/L) & $3.96(2.14-9.97)$ & $4.00(2.29-9.97)$ & $3.38(2.14-4.58)$ & 0.960 \\
\hline Triacylglycerol (mmol/L) & $1.24(0.28-8.40)$ & $1.24(0.28-8.40)$ & $1.26(0.49-2.53)$ & 0.178 \\
\hline PT (s) & $11.7(10.2-17.9)$ & $11.7(10.2-17.9)$ & $12.4(11-14.3)$ & 0.029 \\
\hline Fibrinogen (g/L) & $3.73(1.05-19.7)$ & $3.61(1.05-19.7)$ & $4.62(2.08-6.78)$ & 0.001 \\
\hline D-dimer (mg/L) & $0.515(0.100-55.3)$ & $0.47(0.10-55.3)$ & $0.92(0.29-18.07)$ & 0.420 \\
\hline CK (IU/L) & $0.84(0.18-9.51)$ & $0.82(0.18-9.51)$ & $1.16(0.34-2.46)$ & 0.875 \\
\hline Myoglobin (ng/mL) & $32.38(9.92-282.83)$ & $31.44(9.92-282.83)$ & $40.78(18.15-270.34)$ & 0.004 \\
\hline $\mathrm{BNP}(\mathrm{pg} / \mathrm{mL})$ & $67.44(0-5398.00)$ & $59.82(0-5398)$ & $121.65(6.72-1150.00)$ & 0.728 \\
\hline
\end{tabular}

Page 9/14 


\begin{tabular}{|lllll|}
\hline $\mathrm{PCT}(\mathrm{ng} / \mathrm{L})$ & $0.042(0-4.320)$ & $0.04(0-4.32)$ & $0.065(0-1.080)$ & 0.000 \\
\hline $\mathrm{CD}^{+} \mathrm{T}$ cell $(/ \mu \mathrm{L})$ & $807(164-2284)$ & $825(164-2284)$ & $510(166-1182)$ & 0.002 \\
\hline $\mathrm{CD}^{+} \mathrm{T}$ cell $(/ \mu \mathrm{L})$ & $484(59-1705)$ & $508(59-1705)$ & $378(59-754)$ & 0.003 \\
\hline $\mathrm{CD} 8^{+} \mathrm{T}$ cell $(/ \mu \mathrm{L})$ & $262(43-951)$ & $271.5(43-951)$ & $195(79-417)$ & 0.008 \\
\hline $\mathrm{CD} 19^{+} \mathrm{T}$ cell $(/ \mu \mathrm{L})$ & $152(18-986)$ & $156(18-986)$ & $123(31-395)$ & 0.031 \\
\hline $\mathrm{CD} 16^{+} / \mathrm{CD} 56^{+} \mathrm{NK}$ cell $(/ \mu \mathrm{L})$ & $128(12-677)$ & $134(12-677)$ & $88(22-278)$ & 0.012 \\
\hline $\lg \mathrm{A}(\mathrm{g} / \mathrm{L})$ & $2.22(1-11)$ & $2.22(1-11)$ & $2.36(1-8)$ & 0.074 \\
\hline $\lg \mathrm{G}(\mathrm{g} / \mathrm{L})$ & $11.4(6-30)$ & $11.3(6-30)$ & $12.6(6-17)$ & 0.947 \\
\hline $\lg \mathrm{M}(\mathrm{g} / \mathrm{L})$ & $0.89(0.26-2.52)$ & $0.92(0.26-2.52)$ & $0.70(0-2)$ & 0.040 \\
\hline $\lg \mathrm{E}(\mathrm{g} / \mathrm{L})$ & $37.7(0-2220)$ & $38(0-2220)$ & $33.6(0-590)$ & 0.897 \\
\hline
\end{tabular}

NOTE: Quick sequential organ failure assessment, qSOFA; White blood cell, WBC; neutrophil count, NEU; Neutrophils/Lymphocyte ratio, NLR; hemoglobin, HGB; platelet count, PLT; prothrombin time, PT; alanine aminotransferase, ALT; aspartate aminotransferase, AST; $\gamma$-glutamyl transpeptidase, GGT; albumin, ALB; total bilirubin, TBIL; Direct bilirubin, DBIL; uric acid, UA, creatinine, Cr; creatine kinase, CK; lactate dehydrogenase, LDH; Brain Natriuretic Peptide, BNP; procalcitonin, PCT; c-reactive protein, CRP.

Table 3 Univariant and multivariant COX regression model for progression from mild/moderate cases into severe case.

\begin{tabular}{|c|c|c|c|c|}
\hline \multirow[t]{2}{*}{ Variables } & \multicolumn{2}{|c|}{ Univariable logistic regression } & \multicolumn{2}{|c|}{ Multivariable logistic regression } \\
\hline & OR (95\%) & $P$ value & OR (95\%) & $P$ value \\
\hline \multicolumn{5}{|l|}{ General information } \\
\hline Age, $>75$ years & $1.03(1.01-1.06)$ & 0.01 & $3.92(1.61-9.73)$ & 0.003 \\
\hline Sex, male & $1.494(1.02-2.184)$ & 0.038 & $1.67(0.55-5.09)$ & 0.364 \\
\hline \multicolumn{5}{|l|}{ Comorbidities } \\
\hline Pulmonary disease & $3.625(1.092-12.032)$ & 0.035 & $11.20(2.50-49.70)$ & 0.001 \\
\hline Liver disease & $3.304(1.146-9.527)$ & 0.027 & $1.27(0.26-6.34)$ & 0.768 \\
\hline \multicolumn{5}{|l|}{ Laboratory findings } \\
\hline Lymphocyte $<1 \times 10^{9} / \mathrm{L}$ & $0.215(0.087-0.529)$ & 0.001 & $0.73(0.19-2.81)$ & 0.646 \\
\hline NLR & $1.074(1.012-1.140)$ & 0.019 & $0.73(0.19-2.81)$ & 0.646 \\
\hline AST $>40 \mathrm{U} / \mathrm{L}$ & $1.008(1.001-1.020)$ & 0.017 & $4.60(1.31-16.00)$ & 0.018 \\
\hline Urea (mmol/L) & $1.066(1.020-1.115)$ & 0.005 & $1.92(0.64-5.71)$ & 0.243 \\
\hline PT (s) & $1.482(1.042-2.109)$ & 0.029 & $1.63(0.63-4.24)$ & 0.315 \\
\hline $\mathrm{Cr}>133 \mathrm{~mol} / \mathrm{L}$ & $1.008(1.001-1.015)$ & 0.017 & $2.87(1.18-6.98)$ & 0.02 \\
\hline $\mathrm{CD}^{+} \mathrm{T}$ cell $(/ \mu \mathrm{L})$ & $0.097(0.995-0.999)$ & 0.003 & $0.5(0.05-5.12)$ & 0.556 \\
\hline $\mathrm{CD}^{+} \mathrm{T}$ cell $(/ \mu \mathrm{L})$ & $0.996(0.992-0.999)$ & 0.008 & $1.18(0.25-5.52)$ & 0.830 \\
\hline $\mathrm{CD}^{+} \mathrm{T}$ cell $(/ \mu \mathrm{L})$ & $0.998(0.997-0.999)$ & 0.002 & $2.32(0.2-27.42)$ & 0.505 \\
\hline CD19+ $\mathrm{T}$ cell $(/ \mu \mathrm{L})$ & $0.995(0.990-0.999)$ & 0.031 & $1.13(0.29-4.41)$ & 0.861 \\
\hline $\mathrm{CD} 16^{+} / \mathrm{CD} 6^{+} \mathrm{NK}$ cell $(/ \mu \mathrm{L})$ & $0.992(0.985-0.998)$ & 0.012 & $3.40(1.31-9.13)$ & 0.014 \\
\hline $\lg M(g / L)$ & $0.260(0.072-0.941)$ & 0.040 & $6.31(1.99-19.60)$ & 0.002 \\
\hline
\end{tabular}

NOTE: Neutrophils/Lymphocyte ratio, NLR; prothrombin time, PT; aspartate aminotransferase, AST; creatinine, Cr. 
Figures

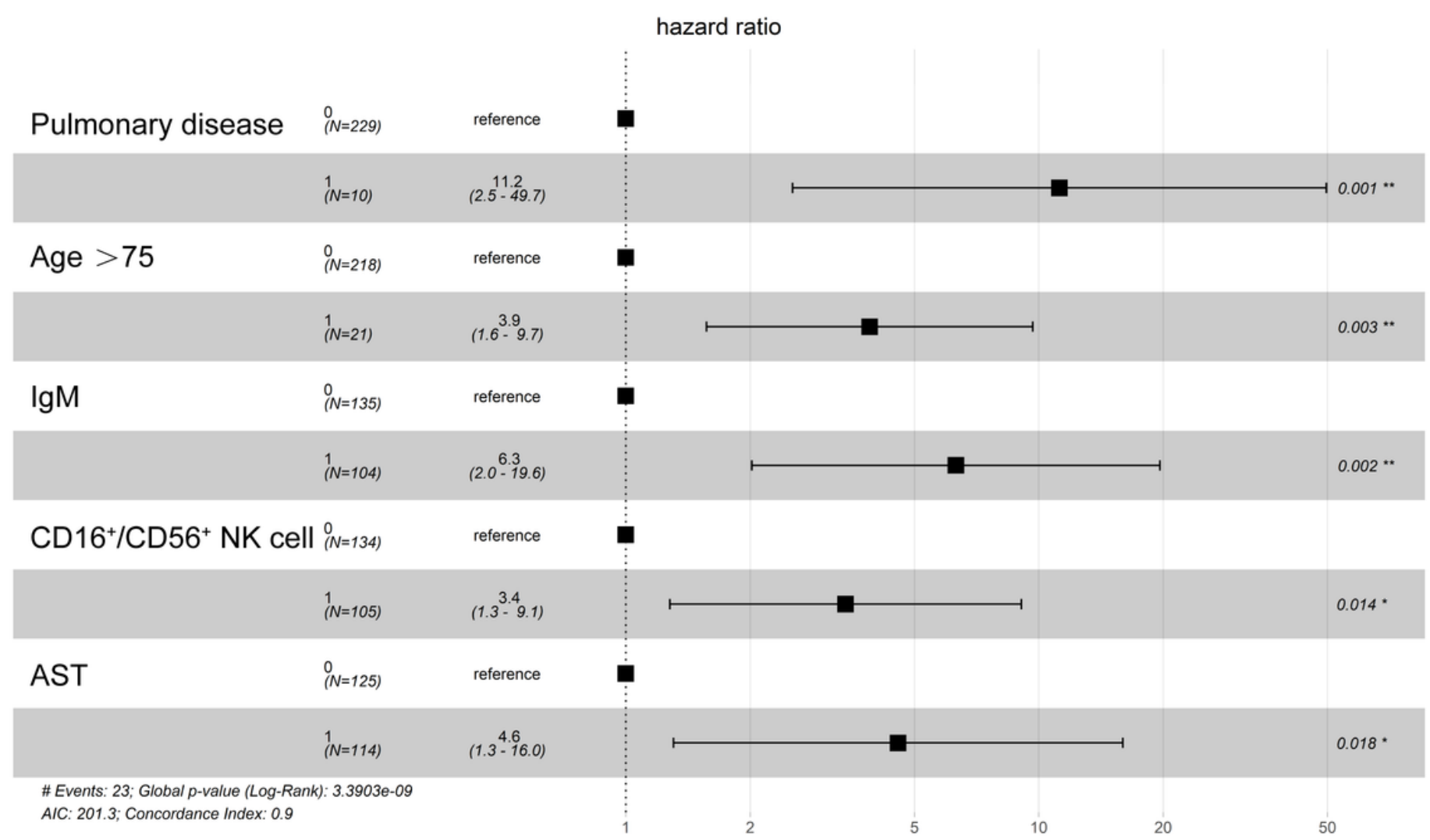

\section{Figure 1}

Forest plot of significant factors in Cox proportional hazards regression model. Shown in the figure are the $\mathrm{HR}$ and the $95 \% \mathrm{Cl}$ associated with the end point. 


\section{Survival Curves}

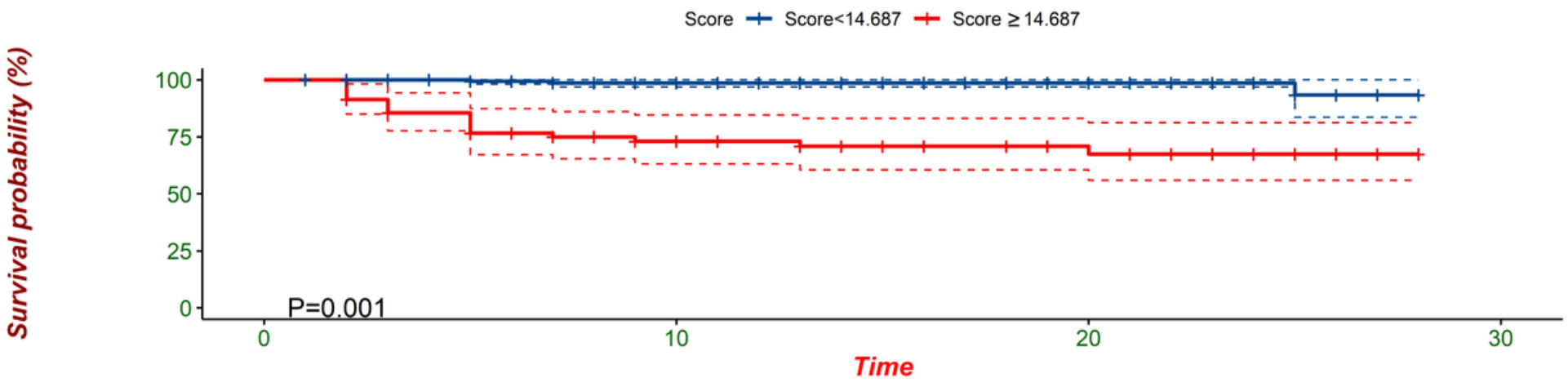

Number at risk

\begin{tabular}{|c|c|c|c|c|}
\hline \multirow{3}{*}{ 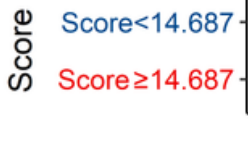 } & 170 & 102 & 41 & 0 \\
\hline & 69 & 36 & 20 & 0 \\
\hline & 0 & 10 & 20 & 30 \\
\hline
\end{tabular}

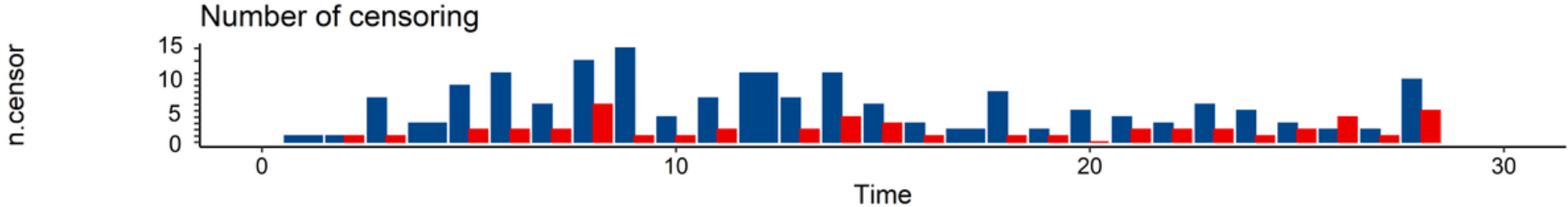

Figure 2

Kaplan-Meier survival curve analysis of the PAINT score.

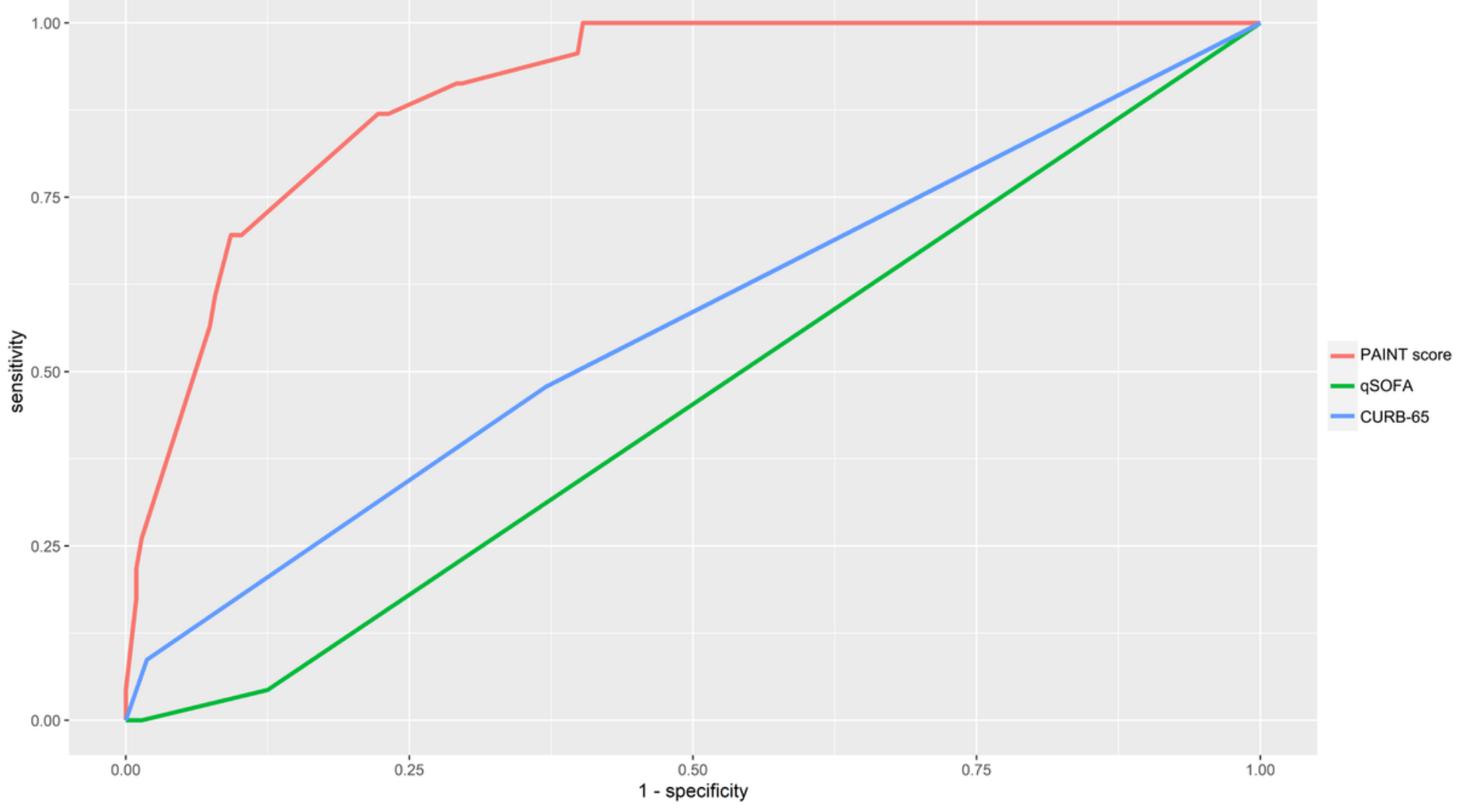

Figure 3 
ROC analysis was used to evaluate the efficacy of PAINT score model for predicting COVID-19 patients' progression from mild/moderate cases into severe cases. C-index values and the corresponding $95 \%$ Cls were estimated for each main study time point to assess the score's discrimination ability. P values represent the statistical significance of the differences between new score and the other prognostic score or factor.

A

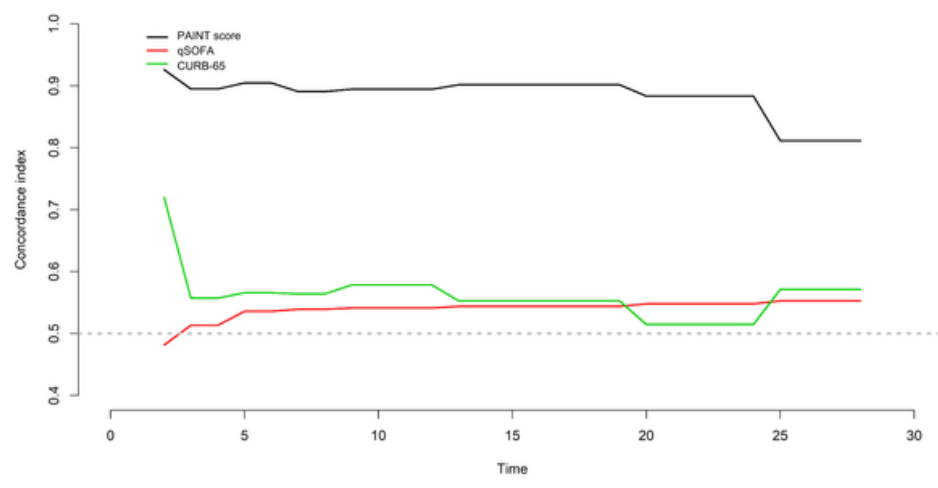

B

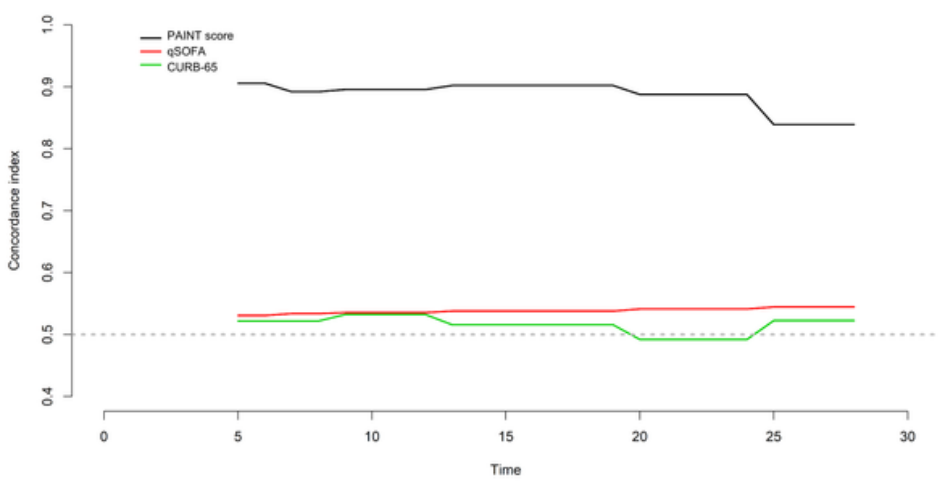

Figure 4

For internal validation of the ability of the PAINT score model, we performed concordance index analysis (a) and 1000 times bootstrap (b) internal validations to evaluate the discrimination for the PAINT score.

a

Points

Pulmonary disease

Age $>75$

$\lg M$

$\mathrm{CD}^{\prime} / \mathrm{CODS6}^{\prime} \mathrm{NK}$ cell

AST

Total Points

28-days progression
Diagnostic possibality
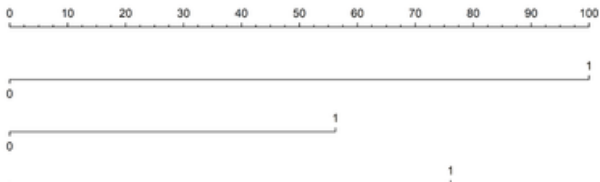

C

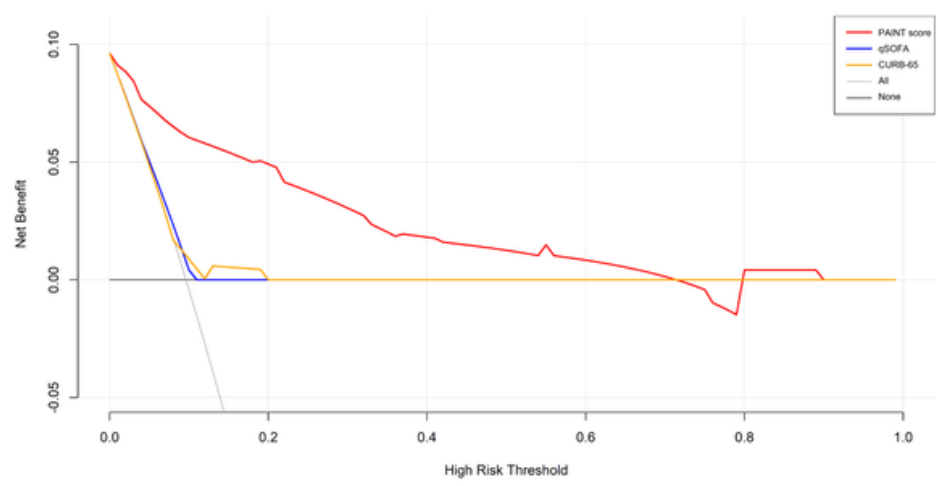

b

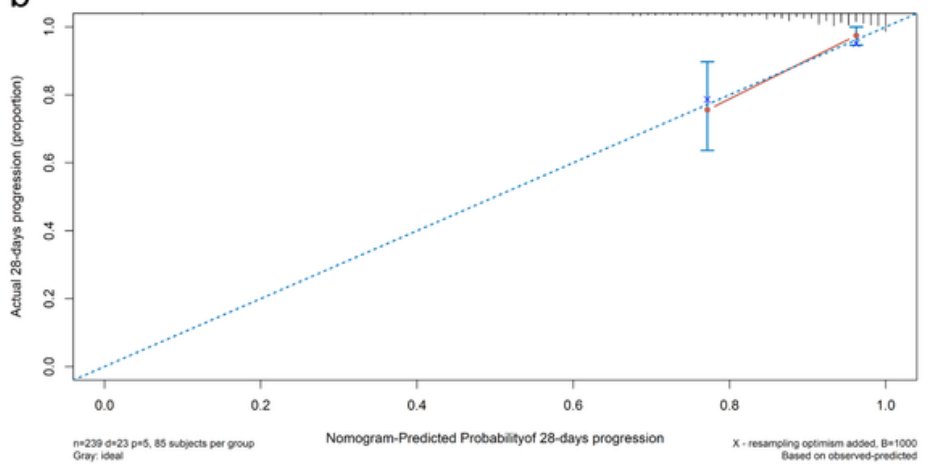

d

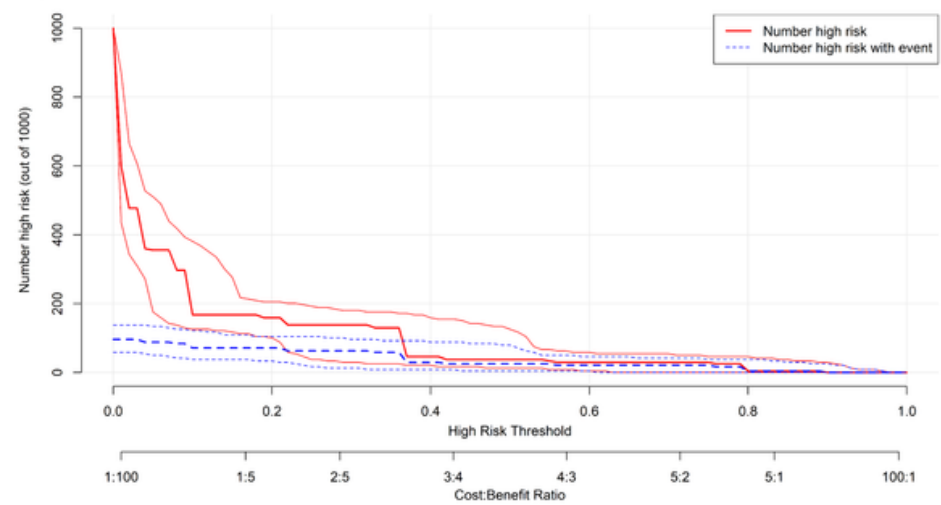

Figure 5

Nomogram, calibration, decision curve and clinical impact curve for progression from mild/moderate cases into severe cases. (a) Nomogram. To use the nomogram, the value of an individual patient is located on each variable axis, and a line is drawn upward to determine the number of points received for each variable value. The sum of these numbers is located on the total point axis, and a line is drawn downward to the survival axes to determine the likelihood of 28-days severe progression. (b) Calibration. The nomogram-predicted probability of non-severe survival is plotted on the x-axis and that of actual non-severe survival is plotted on the $y$-axis. (c) Decision curve. The abscissa of this graph is the threshold probability and the ordinate is the net benefit. (d) Clinical impact curve. The red curve (number of 
high-risk individuals) indicates the number of people who are classified as positive (high risk) by the model at each threshold probability; the blue curve (number of high-risk individuals with outcome) is the number of true positives at each threshold probability.

\section{Supplementary Files}

This is a list of supplementary files associated with this preprint. Click to download.

- SupplementaryTable1.docx

- SupplementaryTable2.docx

- figures1.tif

- figures2.tif

- figures3.tif

- figures4.tif

- figures5.tif

- rawdata20200912.xIsx 